\title{
Work Motivation and Belief in One's Capabilities to Continue Working Among Ageing Home Care Nurses: A Qualitative Study With a Mixed Methods Approach
}

Stina Wallin ( $\nabla$ stina.wallin@abo.fi )

Abo Akademi Vasa https://orcid.org/0000-0002-1810-1972

Anncristine Fjellman-Wiklund

Umeå university

Lisbeth Fagerström

Abo Akademi Vasa

Research article

Keywords: ageing workers, home care aides, occupational health, personal resources, sustainable working life, quality of working life, qualitative research, quantitative measure

Posted Date: September 22nd, 2020

DOI: https://doi.org/10.21203/rs.3.rs-66165/v1

License: (c) (1) This work is licensed under a Creative Commons Attribution 4.0 International License.

Read Full License 


\section{Abstract}

Background The need for home care services is increasing. Therefore, it is important to support an ageing home care workforce to remain in work for longer. Personal resources such as work motivation are important in maintaining home care services, and the belief in one's capabilities contribute to work ability. Few studies have targeted the ageing workers' personal resources to manage their final working years. This study explore ageing home care nurses' (HCNs) experiences of what positively and negatively affects their work motivation, and their beliefs in their capabilities to work until the expected retirement age, and to what extent.

Methods This qualitative study was part of a cross-sectional survey answered by ageing HCNs. In four open-ended questions, aspects regarding work motivation and beliefs in one's own capabilities to continue working until the expected retirement age were asked. Data was analysed using manifest qualitative content analysis. Through a quantification of the qualitative data analysis, the quantifiable focus among the responses was explored.

Results The open-ended questions yielded 2339 utterances from $235 \mathrm{HCNs}$. The categories that gathered the most utterances positively affecting work motivation were named "Work environment", "Significance of work", "Stimulating challenges", and "External response". Correspondingly, categories mainly negatively affected work motivation were, "Organizational work environment", Time constraints", "Job characteristics", and "Work community". Factors that mostly provided the belief in one's own capability to continue working yielded the categories "Own health", "Workplace resources", "Meaning of the work", and "Nature of the work". "Health related decline", "Multifaceted work", "Organizational resources", and "Work related strain" mainly negatively affected the belief in own capabilities. Ageing itself was not seen as a concern.

Conclusions When the factors that concurrently affected work motivation and one's belief to continue working were well-functioning, they positively affected both motivation and belief. When they were insufficient they negatively affected either or both motivation and/or belief. Through highlighting the positive aspects of home care nursing, both work motivation and the belief to continue working might be facilitated among ageing HCNs. Meaningfulness of work should be addressed, together with strengthening the work community, a supporting leadership and offering challenging but overcoming demands.

\section{Background}

In home health care, workers are the greatest resource, since a lack of workers means limited service (1). However, a large percentage of home care staff is ageing $(2 ; 3)$. Little emphasis is put on the aging workers' resources and motivation to manage their final working years (4). When workers decide to stay in work or to leave working life, a combination of individual and work-related factors play a role (5), and therefore, a combination of both is needed to retain workers longer in work life. (6). Personal resources 
together with job resources have been found to moderate the negative effects of age on work ability (7). Personal resources as motivation for home care nurses $(\mathrm{HCNs})$ is important in maintaining home care services (1), and self-efficacy contribute to work ability among home care staff (8). However, few studies have targeted the ageing workers' personal resources (6). Therefore, it is essential to probe personal resources providing ageing $\mathrm{HCNs}$ to remain in work longer.

The need for care is expected to escalate because of the growing number of older people (9), and many countries aim to increase the supply of home care services $(1 ; 10 ; 11)$. One reason is that home care is a cheaper alternative to institutional care, and the potential for informal care is reduced despite its great importance $(1 ; 10)$. In addition, most people prefer to receive care in their homes instead of institutional care. Home care work in Finland entails day-to-day assistance and nursing to help clients cope with their everyday needs and activities, including a wide range of personal, health care related and reabling tasks (2). A challenge in the home care sector is the shortage of staff $(10 ; 12)$, and one of the reasons for this is the unfavourable working conditions (10). In Nordic countries, HCNs have experienced recent changes in home care negatively, and about $40 \%$ have considered quitting their work (2; 3$)$. An increased physical and mental workload was observed (2). HCNs expressed concerns about both the quality of home care and the safety of the clients, as well as their own health. Trust in their supervisors had deteriorated. However, HCNs experienced meaningfulness of work.

Practices supporting ageing workers are mostly focusing on reducing job demands and increasing job resources, and seldom on enhancing personal resources (6). Although, personal resources are found to be important for work ability and wellbeing throughout the entire work career (7). Focus on factors that motivates ageing workers to stay in work is important (13); however, it is a great demand (14). A key to continue working until retirement age is intrinsic motivation (15), i.e. performing an activity for its own sake in order to achieve satisfaction (16). Universally, work motivation does not decline with age, as considered by former negative stereotypes (17). However, factors influencing work motivation may differ in different cultures and contexts of nursing practice (18). Work motivation influences the quality of healthcare (18), and the importance of the HCNs' motivation for maintaining home care services has been emphasized (1). An important personal resource connected to motivation and wellbeing at work is self-efficacy $(19 ; 20 ; 21)$. Despite much research on self-efficacy, less is known about the role that occupational self-efficacy plays for the ageing work force (19). Occupational self-efficacy describes one's beliefs in one's own capabilities to successfully perform in an occupational domain in respect to occupational adjustment and the management of obstacles (22). Occupational self-efficacy is positively related to intrinsic motivation among older workers (19), and to higher work ability among HCNs (8). Occupational self-efficacy is important when developing interventions for older workers $(19 ; 23)$, and when promoting work ability and health among HCNs (8). Consequently, workplace interventions need to focus on enhancing self-efficacy besides job resources and job demands (8).

The aim of this study is to explore ageing HCNs' experiences of what positively and negatively affect their work motivation and their beliefs in their capabilities to work until expected retirement age, and to what extent. 


\section{Methods}

\subsection{Study design}

This study had an exploratory qualitative design with a mixed approach (24), and was part of a crosssectional survey study.

\subsection{Setting, data collection and participants}

The study was part of the larger research project "Personal resources supporting work ability", aiming to provide knowledge about ageing workers' personal resources during their final working years. In this study, we considered ageing workers 45 years and older, to increase the possibility for preventive measures (25). The survey was carried out in May to September 2018. The questionnaire was sent to both $\mathrm{HCNs}$ and engineers, yet the qualitative results for the $\mathrm{HCNs}$ are presented in this article. From a region of Western Finland with mostly rural areas, HCNs were recruited using their supervisors. Eight municipalities and cities, conducting home care services by themselves, and two social- and health services consortiums consisting of three to four municipalities or cities each were included. All HCNs, 45 years and older, were recruited to answer an anonymous paper-based or web-based questionnaire available in Swedish or Finnish languages. The questionnaire included four open-ended questions, which composed the source of this study. In these questions, the HCNs were asked to mention three factors that positively affect and three factors that negatively affect their work motivation, and correspondingly that positively and negatively affect their beliefs in their own capabilities to continue working until the expected retirement age (Fig. 1). Additionally, the questionnaire included Work Ability Index (WAI) (26), Utrecht Work Engagement Scale (UWES-9) (27) and Occupational Self-Efficacy Scale - Short Form (OSSSF) (22). These results are presented elsewhere (submitted, under review). WAI, OSS-SF and UWES-9 are free to use for research purposes, yet sharing raw test-scores from UWES-9 with the authors of the scale. The questionnaire used was developed for this study project, and an English translation is provided as Additional File 1.

Out of 460 invited participants, $235 \mathrm{HCNs}$ answered the questionnaire after three reminders, yielding a response rate of $51 \%$. Participants were $45-66$ years old, and the majority were women with an average of 18 years work experience in home care (Table 1). Two thirds of the participants had averagely good work ability. 
Table 1

Characteristics of the study population $(n=235)$

\begin{tabular}{|c|c|}
\hline Age (years) & $55(55), 5.3$ \\
\hline $45-49$ & 19.4 \\
\hline $50-54$ & 26.6 \\
\hline $55-59$ & 31.1 \\
\hline $60-66$ & 23.0 \\
\hline \multicolumn{2}{|l|}{ Gender } \\
\hline Women & 99.1 \\
\hline Men & 0.9 \\
\hline \multicolumn{2}{|l|}{ Marital status } \\
\hline Single & 8.3 \\
\hline Married/marriage-like relationship & 80.3 \\
\hline Divorced & 11.0 \\
\hline Widow & 0.4 \\
\hline \multicolumn{2}{|l|}{ Native language } \\
\hline Swedish & 57.3 \\
\hline Finnish & 42.7 \\
\hline \multicolumn{2}{|l|}{ Educational level } \\
\hline No vocational training & 2,7 \\
\hline Vocational degree & 65,5 \\
\hline Higher vocational education & 28,3 \\
\hline Master's degree or higher education & 3,5 \\
\hline \multicolumn{2}{|l|}{ Employment status } \\
\hline Permanent employment & 88.3 \\
\hline Temporary employment & 11.7 \\
\hline Full-time employment & 73.0 \\
\hline Part-time employment & 27.0 \\
\hline \multicolumn{2}{|l|}{ Job demands } \\
\hline Mentally demanding & 18.5 \\
\hline
\end{tabular}




\begin{tabular}{|c|c|}
\hline Age (years) & 55 (55), 5.3 \\
\hline Physically demanding & 5.6 \\
\hline Mentally and physically demanding & 75.9 \\
\hline Work experience (years) & $18(18), 12.1$ \\
\hline Work ability index & $38(40), 6.8$ \\
\hline Occupational self-efficacy & $5.9(6.0), 0.8$ \\
\hline Work engagement & $5.1(5.3), 0.9$ \\
\hline \multicolumn{2}{|c|}{ The numbers are either \% or mean (median), standard deviation } \\
\hline
\end{tabular}

In this qualitative study, manifest content analyses was used, both qualitatively and quantitatively, i.e. the content analyses was conducted with a mixed method approach $(24 ; 28)$. Using a mixed approach enables a better understanding of the complex topic, using the strength of integrating both qualitative and quantitative analyses to generate new knowledge. A manifest qualitative content analysis $(24 ; 29$; 30) gained a deeper knowledge and understanding of ageing HCNs' work related motivation and beliefs. Answers from the open-ended questions were organised in Microsoft Excel, with answers from each participant in a separate row. To become familiar with the text, all responses were read through several times. From each question, responses were grouped into topics based on similarities and dissimilarities in content to describe all aspects of the content. Further, for each question separately, the topics were analysed by manifest qualitative content analysis. The condensed text was coded, and to find similarities and differences, the codes were compared and interpreted repeatedly. Codes with similar content were sorted into sub-sub-categories and sub-categories. Finally, sub-categories pertaining to the same topic were sorted into categories that corresponded to the meaning of the material, the context and the aim. To confirm conformability, investigator triangulation was used. SW made the initial analysis of the responses into similar topics, and condensed the text. In addition to SW, AFW and LF read the condensed answers and the codes independently, and the codes were compared and discussed until agreement was reached $(24 ; 29 ; 30)$. Furthermore, a quantitative analysis reporting the frequencies and percentages enabled to examine where the main point in $\mathrm{HCNs}$ ' responses was located in the large amount of data (2339 utterances from the four questions taken together). The identified topics were quantitatively ranked, based on the frequencies of which the topics were mentioned in all of the data for each openended question (24). In the aim, the data analysis, results and discussion, an integration of both the qualitative and the quantitative approach was used $(24 ; 28)$.

\section{Results}

There were 659 utterances related to factors positively affecting work motivation ( $n=225,96 \%)$, and 620 utterances negatively affecting work motivation $(n=227 ; 97 \%)$. Regarding factors positively affecting 
one's beliefs in one's own capabilities to continue working until expected retirement age, 553 utterances were emphasized $(n=218 ; 93 \%)$, while 507 utterances were related to negatively affecting beliefs $(n=$ $202 ; 86 \%)$. Typically, the participants gave between one to three responses for each question. For each question separately, the categories that gathered the most utterances, and their sub-categories, are more closely presented below. The frequencies of categories for each question are presented in Fig. 2, and the results of the qualitative content analysis, including quotations in Table 2. 
Table 2

The results of the qualitative content analysis

\section{Factors positively affecting work motivation \\ $\mathrm{n}=225$ (96\%), 659 utterances}

$\begin{array}{ll}\text { Categories } & \text { Sub-categories } \\ \begin{array}{l}\text { Work } \\ \text { environment }\end{array} & \begin{array}{l}\text { Satisfaction with } \\ \text { colleagues }\end{array} \\ \begin{array}{l}\text { (234 } \\ \text { utterances) }\end{array} & \begin{array}{l}\text { Satisfaction with } \\ \text { leadership and } \\ \text { organizational resources }\end{array}\end{array}$

Quotations

being with coworkers [makes me feel good]

wonderful workmates and the cooperation we have

good and supportive work team

have influence over own work, can affect

to have a good supervisor, who listens etc.

Significance Meaningful work "experience that the work is important"

of the work

(161

Enriching client

meetings

the feeling that you make a difference in the elderly's everyday life

to get to work with elderly people

get so much back from the clients

Stimulating Multifaceted work

challenges

(131

Competence and desire

to develop

it isn't monotonous work, something happens all the time

work independently, must make own decisions

challenging, requires physical and mental fitness as well as social skills

I feel I can do my job

opportunity to develop, learn new things

External Recognition from clients

response and relatives

$\begin{array}{ll}\text { (77 utterances } & \begin{array}{l}\text { Recognition from } \\ \text { colleagues and } \\ \text { management }\end{array}\end{array}$ gratitude from clients and relatives

when a client thanks [you] for the help and is satisfied with the care

positive feedback from coworkers

appreciation from superiors

Factors negatively affecting work motivation

$n=227(97 \%), 620$ utterances

Categories

Sub-categories

Quotations 


\section{Factors positively affecting work motivation \\ $n=225$ (96\%), 659 utterances}

\section{Organizational Lacking resources \\ work \\ environment \\ Unsatisfactory leadership}

(176

utterances)

not equipment to get the job done

one should constantly take in so many darn new things

existing knowledge is not utilized

if superiors don't listen or don't care

unappreciative head nurse, only hear how bad we are

poor management - don't understand our job

\section{Time Significant rush and}

constraints

(144

utterances) stress

Negative consequences

of time pressure hurry, tight work schedules that others plan

not knowing whether you have time to eat during the work day

lack of time [with] the clients, just in a hurry all the time

the lack of time - not having the time to perform one's tasks

things that are left unfinished

change of clients, that you are not allowed to care for the same clients but are instead forced to change daily $=$ IRRITATING

home care clients are becoming more and more complex, and everything should be documented

wintertime when the roads are icy, poorly plowed, and early spring with poor road conditions

would like to continue to educate myself at regular intervals but it's difficult to manage with full-time job

little possibility to influence decisions, even though I, for example, know something better than those who decide

It is not always so fun 


\section{Factors positively affecting work motivation \\ $n=225$ (96\%), 659 utterances}

Work

community

(74

utterances)
Negative atmosphere

Poor engagement

bad atmosphere among the personnel

gossip, mean talk behind your back

poor work ethic among colleagues

if you can't trust your workmates (that the work has been done)

\section{Factors positively affecting belief in one's own capabilities to continue working until expected} retirement age

\section{$n=218(93 \%), 553$ utterances}

Categories Sub-categories Quotations

Own health

(140

utterances)
A resource and a challenge

Health supporting activities

if [my] health stays the same as now, it will be ok you don't know whether you are capable until retirement because of the workload

I must take care of myself so that I am capable hope to be able to improve [my] work ability

Workplace resources

(118 utterances)
Satisfactory organizational resources

Strong workplace community support and encouragement from my supervisor

that the employer recognizes age in a positive way

the support from work colleagues

our fine sense of community in the work team
Meaning of Satisfaction from work the work (97 utterances)

\section{Intrinsic motivation}

successful client meetings

[I] enjoy my work tasks

[1] like to help people

the feeling of making a difference

love for my own work 


\section{Factors positively affecting work motivation \\ $n=225$ (96\%), 659 utterances}

Nature of the Job stability

work

(94

Skilled in demanding

utterances) work

there are always sick people

home care is also needed in the future

I don't feel old, I still want to learn new things

master different situations

that the work pace shouldn't be pushed to the breaking point

Factors negatively affecting belief in one's own capabilities to continue working until expected retirement age

$\mathrm{n}=202(86 \%), 507$ utterances

Categories Sub-categories Quotations

Health-related Current life and health

decline

(145

Future health challenges

utterances)

Multifaceted

work

$(115$

utterances)

Imbalance between

resources and demands there is no such thing, unless [my] health fails

the pain that is getting worse

that [my] body is not capable of the work

I don't know if I am capable of 'running' to the end, probably not

shift work, heavy shifts on the weekends the importance of anything else but patient contact

ever-increasing demands on knowledge

elderly people should live at home longer... But less personnel who should manage to get more done

if the workload increases more

too unvaried tasks without challenges 


\section{Factors positively affecting work motivation \\ $n=225$ (96\%), 659 utterances}

Organizational Consequences of lack of resources resources

(96 Unsatisfying leadership

utterances)

Work-related

strain

$(65$

utterances)

Constantly present rush

Imminent threat of stress too few personnel, not competent personnel

permanent fixed-term employment contracts

"that we don't get more personnel when the number of clients increases

constant changes, which have often not been considered to the very end either, you can't trust things

the worker is of less and less importance

[they] don't listen to the workers

unfair distribution of work, does not apply to everyone

stress/always a rush during work

too much of a rush with the clients

sometimes sleep poorly; the job is in [my] thoughts...

if... the stress increases more...

\subsection{Factors positively affecting work motivation}

The category "Work environment" (234 utterances), included the sub-categories "Satisfaction with colleagues" and "Satisfaction with leadership and organizational resources", generated the most frequent responses. Work environment as a motivational factor was due to both colleagues and leadership, as well as resources to carry out work tasks. Satisfaction with colleagues included good relationships, and a feeling of having a connection with each other. Colleagues who felt that they were liked, conveyed a sense of wellbeing. It was essential to have a particular place in the work community. Well-functioning teamwork was emphasized, it was considered effective and a product of reliable and supportive colleagues with good collaboration skills. Enjoyment and well-being at work led to work pleasure. However, the HCNs' own attitude to work was of importance for work motivation. Satisfaction with leadership included that the labour management trusted the HCNs; and allowed them to take responsibility and influence their work content, routines, work schedules, work quantity, and vacations. Another factor mentioned was to be able to perform other tasks for a change or supervise new colleagues. Furthermore, good supervisors, applying a supportive leadership style, including having a good attitude with workers and good dialogue skills were emphasized. If the necessary organizational resources were available, which were required to perform the job, it was possible to complete high quality work. This included appropriate work equipment, and good planning of work, for example functioning 
work schedules, sufficient staff, and sufficient time to perform client work, appropriate workload and peace and quiet to perform work.

The category "Significance of the work" (161 utterances) generated the second highest amount of responses, and included the sub-categories "Meaningful work" and "Enriching client meetings". Home care work was described as both meaningful in order to help clients in their everyday life, but also a work driven by inner motives to help. Home care work as a profession was perceived being in line with the HCNs' own holistic view. Home care work was considered important, meaningful and a necessary, allowing possibilities to make a difference in people's lives. An intrinsic motivation to help other people was emphasized; having the will, ability, and permission to help clients in their everyday life, and to bring them happiness. HCNs enjoyed to work with the clients and cared for their well-being. Furthermore, home care work entailed recurrent social contacts; HCNs got to know their clients well, and felt close to them. However, not only did the HCNs help the clients; the clients' welcoming reverberated positive feelings back to the HCNs.

The category "Stimulating challenges" (131 utterances), included the sub-categories "Multifaceted work" and "Competence and desire to develop", emphasized typical duties of the work. Home care nursing was described as both varying and challenging, being encouraged to use many different skills and to further education. Home care nursing comprised both responsibility and freedom. The ability to do shift work and the work content were brought up. The work was unpredictable and varying, with different tasks every day and work in different places, mostly in the clients' homes. There were challenging tasks and client situations, requiring both physical and mental power as well as social skills. According to HCNs, they had the work they desired and were educated for, allowing them to work in an interesting branch. Work experience and professional skills were emphasized. HCNs trusted themselves and had confidence in their skills and competence. They felt strengthened by results of work done and success in problem solving. Likewise, they wanted to continue developing their professional skills and attend additional work education.

The category "External response" (77 utterances) gathered the fourth most frequent responses, and yielded the sub-categories "Recognition from clients and relatives" and "Recognition from colleagues and management". Positive feedback received externally from others for work done seemed to be of importance to gain motivation to continue working. Feedback received from the clients appeared as appreciation, praise and encouragement. A hearty welcome from the clients, who were grateful for getting help and a good care improved motivation. Likewise, recognition from relatives showing their thankfulness for good care were expressed. Positive feedback from colleagues as encouragement and displayed satisfaction were found to be important, as well as supervisors and employers expressing their appreciation.

Moreover, less frequently mentioned responses increasing motivation were "Income stability" (32 utterances), "Close relationships and leisure" (18 utterances), and "Sufficient health and energy" (6 utterances). 


\subsection{Factors negatively affecting work motivation}

The most frequent responses negatively affecting work motivation yielded the category "Organizational work environment" (176 utterances), and the sub-categories "Lacking resources" and "Unsatisfactory leadership". Consequences of shortages in resources as well as unsatisfying leadership influenced the work environment. Due to a reduction in financial resources and optimization, worsening care conditions, resources not meeting the needs of care, and inequalities between work teams were revealed. HCNs stressed inadequate or lack of necessary work tools, inappropriate workspaces, and poor indoor air quality. Frequent changes caused concern, as they often occurred at short notice, and were perceived both difficult and burdensome. Changes were seen in existing responsibilities as well as in new tasks and new ways of working. Both incompetence among the permanent workers and difficulties in finding skilled staff were stated. Nevertheless, accessible skills among HCNs remained sometimes unused. Moreover, a negative effect on work motivation was a weak leadership. Significantly leaders' negative attitude towards workers, and their lack of response, support and appreciation. Insufficient dialogue between workers and leaders was emphasized, including poor information, work instructions and guidance at work. Leaders being inaccessible, escaping their responsibilities or making too high demands, sometimes without adequate follow-ups. Injustice in everyday work, unclear job descriptions, as well as poor work planning and scheduling were accentuated, in addition to HCNs not being involved in the work planning. Further hindrances stressed were unclear criteria and purposes of the home care work, and an overall unsystematic work organization.

The category "Time constraints" (144 utterances) gathered the second most responses, and generated the sub-categories "Significant rush and stress" and "Negative consequences of time pressure". There was a constant time stress causing a negative strain. HCNs perceived their work pace as too high due to time pressure, leading to a considerable and sometimes unreasonable rush. Physical and mental stress were present in everyday work. Among some HCNs, the stress arose periodically, while others considered it a constant and extreme stress. Too many client visits a day and time pressure when driving from one client to another triggered the stress. HCNs were often behind the scheduled time. They experienced less time for completing tasks, and for listening to the clients. Consequently, tasks were left unfinished or undone, with the quality of work suffering and the workload perceived as too hard.

The category "Job characteristics" (119 utterances), yielded the sub-categories "A hard work" and "Lowered ambition", and had the third most frequent responses. The multifaceted nature of home care nursing included demanding challenges affecting the HCNs' energy and get-up-and-go-ahead spirit. Home care nursing as a solitary and highly demanding work requiring great responsibility felt burdensome. HCNs expressed a feeling of uncertainty and being unsatisfied. There were many client visits per day, with often new clients and new tasks. Additionally, the work environment was often non-ergonomic and many clients were physically heavy to assist. Sometimes the work environment was unclean. The shift work was perceived as hard, and additionally home care nurses worked a lot of overtime. In addition, they experienced little opportunity to influence their working hours and schedule, as well as the work routines and job tasks. Not feeling involved in decision making was negatively affecting home care nurses' 
motivation. The amount of administrative work had increased during the last years. It was perceived as taking too much time from the client work, and some assignments were considered unnecessary. Unfinished administrative work was stressful, and besides, HCNs stated deficiencies in documentation, even among ordinary staff. Additionally, there were frequent staff changes with lots of new colleagues. The weather conditions of the seasons were at times challenging. Lots of kilometres were driven by car, sometimes in demanding weather and bad road conditions. Working in the clients' often very warm homes followed by driving in a cold car were conveyed. Alarming was that the already high workload was perceived as increasing, because of a higher amount of work, increasing requirements, and more complex clients with more challenging care needs. HCNs wanted to improve their skills, but at the same time, they experienced declining levels of energy and willingness. The work became an old habit, and the attitude and the feeling towards work became increasingly negative.

The category "Work community" was the fourth most frequently mentioned utterance, (74 utterances), and yielded the sub-categories "Negative atmosphere" and "Poor engagement". A poor work community, including a bad atmosphere and negative and tired colleagues, was negatively affecting work motivation. Poor cooperation and conflicts in the working group along with the complaining of others, arrogance, gossip, slander and jealousy were brought up. In addition, a language barrier between Swedish and Finnish speakers was mentioned, although only by a few HCNs. Lack of commitment and motivation were expressed as poor work ethic and poor activity among the staff; colleagues being lazy, high usage of private mobile phones, and not participating in tasks other than client work. HCNs emphasized poor responsibility among colleagues when tasks were left undone and colleagues were not helping each other even though needed. As a result, a loss of confidence in colleagues was seen.

Other factors negatively affecting work motivation, although mentioned less, were "Weakened health and energy" (35 utterances), "Feedback from clients and relatives" (23 utterances), "Salary level" (23 utterances), "Staff shortage" (19 utterances), "National controlled decrees" (6 utterances) and "Age" (1 utterance).

\subsection{Factors positively affecting the belief in one's own capabilities}

The most frequent response supporting one's confidence to work until the expected retirement age yielded from the category "Own health" (140 utterances), with the sub-categories "A resource and a challenge" and "Health supporting activities". Overall, HCNs conveyed their health as an important resource in work life, worth investing effort in. The health was both a resource and a challenge. The current health and wellbeing provided confidence to continue working among home care nurses with no existing health impairments, or when they were able to manage well with health challenges. However, hope for good physical and mental health to continue were expressed. Existing health declines were perceived as a challenge to continue working. Some HCNs felt anxious about their deteriorating health; they perceived worries about their future work ability and voiced the need to prioritize their health before continue working until the expected retirement age. However, $\mathrm{HCN}$ declared an intention to and an interest in 
promoting and maintaining their health, by participation in rehabilitation programs, and with appropriate physical exercise, rest and eating habits. Some HCNs hoped for a better health after a forthcoming surgery. Only a few HCNs saw support actions as a demand in being capable to continue working.

The category "Workplace resources", received the second most responses (118 utterances), and yielded the sub-categories "Satisfactory organizational resources" and "Strong workplace community". Overall, well-organized work was in high demand, including both material resources, good leadership and good relationships with work mates. Having enough disposable HCNs, both temporary and skilled workers, and retaining existing workers using continuing employment agreements were emphasized. Moreover, supply of the ergonomic tools which are required and the ability to adapt the clients' homes for their care needs, as well as job training to cope with demanding clients were mentioned. A good leader was considered to be supportive, responsive, understanding and encouraging, showing appreciation for efforts made and treating workers equally. HCNs emphasized the importance of participation in work related matters, such as the influence over working hours, workload, work content and opportunities for job rotation. Employers noticing the age of the workers in a positive way was also emphasized to influence confidence. Furthermore, the availability of modified tasks in line with current work ability was stressed, as well as the importance of qualitative occupational health care service. A strong work community was essential. Likable colleagues, who HCNs got on well with, produced job satisfaction. In well-functioning work teams, colleagues supported and helped each other. Sometimes, an even deeper friendship developed. However, the possibility to be able to switch to another work team in the case of poor work community was also highlighted.

The category "Meaning of the work" gathered the third most frequent responses (97 utterances), and generated the sub-categories "Satisfaction from work" and "Intrinsic motivation". The deeper meaning of the work comprised of the clients themselves, the work tasks, and a strong intrinsic motivation of the HCNs. HCNs liked their clients and were very pleased to work with them. The client relations provided social interaction and rewarding meetings that strengthened motivation. Moreover, HCNs were satisfied with the work tasks and their workplaces. HCNs enjoyed and got pleasure out of their work. A great intrinsic motivation and a strong desire to help and take care of people were emphasized. HCNs experienced their work as meaningful, and highlighted the large amount of people in need of assistance. They stressed feelings of love for their work, and stated home care nursing as their dream profession. A work where their own work morale was essential.

The category, "Nature of the work" (94 utterances) had the fourth most frequent responses, and yielded the sub-categories "Job stability" and "Skilled in demanding work". The multifaceted and challenging home care work provided opportunities to develop and use professional skills, as well the fact that there are a large amount of available positions within this field. The home care profession was stated as a stable work, since there is a continuous need of work staff, and future demand due to the changes in the society concerning more people living at home for longer. The sense of security to continue working within the same field and work team was also expressed. HCNs appreciated the multifaceted nature of home care. They experienced themselves as skilled, with confidence in managing the varying work tasks. 
They saw continued changes and work related challenges as inspiration, as they were motivated to develop their own professional skills. However, HCNs longed for reasonable mental and physical workload, as well as for a better status for the home care work.

Furthermore, but in less degree, the categories "Family life and leisure" (35 utterances), "Joy of living and wisdom" (32 utterances), "Income needed" (18 utterances) and "Appreciation and feedback" (17 utterances) emerged. Two people had not thought about what provided them with confidence to continue working.

\subsection{Factors negatively affecting beliefs in one's own capabilities}

The category "Health-related decline" (145 utterances) gathered the most frequent responses, yielding the sub-categories "Current life and health" and "Future health challenges". Simply if the overall health remains; the HCNs did not see any hindrances to continue working until the expected retirement age. However, the current health and balance in life revealed challenges. HCNs brought up a long list of diagnosed diseases, such as mental health disorders, musculoskeletal diseases, and hypertension. Many reported aches and pains in the back, shoulders, knees or fingers. Due to the current health limitations, HCNs expressed concerns and uncertainties of whether the current diseases will deteriorate, and about future illnesses. Along with physical decline, high mental strain, insomnia, reduced energy and weakened recovery caused uncertainty about the future. Moreover, the concern of close relatives' health were also stressed. However, only a few mentioned their ageing as a concern.

The second most frequent responses generated the category "Multifaceted work" (115 utterances), and the sub-categories "Demanding work" and "Imbalance between individual resources and demands". HCNs stated home care nursing as burdensome. The multifaceted and challenging nature of the work imposed high demands on balancing individual resources. The shift work was hard, with irregular and inconvenient working hours, intense, and too many shifts without days off. Moreover, extended working days, frequent overtime and being asked to work at short notice were brought up. Increased work areas also entailed longer work trips and more travel time in the car. HCNs expressed discontent with the increased amount of administrative tasks, sometimes at the expense of client work. An increased requirement on knowledge was experienced, and some HCNs stressed an inadequate knowledge level in relation to the requirements. Moreover, concerns about an imbalance between individual resources and work demands were emphasized. HCNs revealed an already heavy but still increasing physical and mental workload. There was an increase in the amount of clients, often with more demanding care needs, and yet often less time for caring and assistance. Care giving in clients' homes, often with insufficient ergonomic tools, entailed physical heavy workload. Mentally challenging was the need to be constantly flexible at work, the already high and increasing work demands, as well as the uncertainty about future demands and an even greater workload. HCNs sometimes perceived too much responsibility, and were concerned about the poor quality of the final home care being provided. Dealing with clients and relatives was also stated to be mentally challenging as well. In contrast, lack of challenges, personal development 
and promotional opportunities also negatively affected confidence in being able to continue working until retirement age.

The category "Organizational resources" gathered the third most frequent responses (96 utterances), and yielded the sub-categories "Consequences of lack of resources" and "Unsatisfying leadership". Lacking resources and economic savings was conveyed as staff reductions, understaffing, hiring freezes, despite the need of workforce, incompetent workers and the continuous employment of temporary workers. Due to savings, involuntary team and workplace changes were forced. Home care nursing was exposed to frequent and continuous changes due to the organizational changes, reorganizations and fusions of organizations. Many changes were considered irrational, causing either deterioration or not achieving the expected results, and were mentally stressful and energy draining. Some changes were considered as uncontrollable, and the uncertainty and fear of losing one's job was revealed. Dissatisfaction with leadership and poor leadership skills were emphasized, decreasing HCNs' confidence to work until the retirement age. Lack of support, appreciation, respect, justice and equality were disclosed, as well as unclear or missing information. HCNs experienced that they sometimes were not listened to, and that their supervisors had inadequate understanding of home care nursing. Moreover, excessive demands with no resources for realization were stressed, as well as poor and unfair work distribution.

The category "Work related strain" (65 utterances), which generated the sub-categories "Constantly present rush" and "Imminent threat of stress", had the fourth most frequent responses. A constant rush causing stress reactions was negatively affecting $\mathrm{HCNs}$ ' belief to continue working until the expected retirement age. The hurry was an existing companion in the everyday work, perceived to be further increasing, and too hard. Some HCNs wanted to change work, because of the rush. Concerns about continuous stress was emphasized. Home care nurses expressed reduced stress tolerance, including thoughts about work interrupting their sleep, and that they were worried about future stress aggravated reactions.

In addition, categories with less responses were "Political and national decisions" (23 utterances), "Workplace community" (20 utterances), "Financial reasons" (18 utterances), "Retirement and family life" (7 utterances), "Lack of motivation" (7 utterances), and "Unemployment" (4 utterances). Four utterances stated that nothing could negatively affect their belief of continue working until the expected retirement age, and four people had never thought about it.

\section{Discussion}

The aim of this study was to explore what aspects positively and negatively affect ageing HCNs' work motivation and their belief in their capabilities to work until the expected retirement age. The findings showed that several aspects concurrently affected both work motivation and belief. When the aspects were well-functioning, they positively affected both motivation and belief, and when they were insufficient they negatively affected either or both motivation and/or belief. Our results are supported by many findings from previous research on work motivation and prolonging work life in home care and health 
care sector among mixed aged $(18 ; 31)$ and older nurses (32). Since our study included solely 45 year olds and older HCNs, it conveys important knowledge about ageing HCNs' aspects. Although age management should include all age of workers, addressing ageing workers' needs might help to deal with the lack of skilled health care workers and to promote their work careers (33).

HCNs perceived that their health highly affected their belief in their capabilities to continue working. Current health declines, and concerns about future deteriorations, caused uncertainty. Furthermore, the high physical and mental workload experienced, raised concerns and thoughts to change work field. Wellfunctioning job characteristics, organizational resources, and supportive leadership facilitated motivation and belief, whereas if any of these factors were poor-functioning motivation and belief decreased. Therefore, it is of great importance to obtain a balance between resources and demands, as well as supportive leadership. This is supported by earlier studies. Unmanageable work demands in the nursing sector must be handled $(31 ; 32)$. Feelings of being worn-out influences older workers' decisions on whether to continue working $(32 ; 34 ; 35)$. When having a physical form of work, poor health affecting the work ability may force the worker out of work $(36 ; 37)$. Self-rated health has also been considered a better predictor of extended working life among older health care personnel, compared to diagnosed diseases (35). Self-rated health is highly affected by the workers' perceived work satisfaction (35), as well as having meaningful tasks (38). Moreover, meaningful work is related to both HCNs' work motivation and the intention to remain in work $(2 ; 31)$.

Even though the home care nursing was perceived as both mentally and physically challenging in our study, the autonomy, flexibility and multifaceted character, conveyed both motivation and belief to continue working in conditions of balanced resources and demands. The HCNs felt skilful in their work, and were strengthened by the use of their various skills and succeeding in challenges. Although a reduction in energy was perceived as a hindrance for one's own development, HCNs still wanted to face new challenges and develop in their work. Similar factors have been found to contribute to HCNs intention to continue working (31). Positive valued demands might have a motivational potential (39), since enough job resources are available $(40 ; 41 ; 42)$. Among elderly care nurses it has been noticed that they want to improve the care being provided (32). Thus, HCNs should be offered opportunities for continuous education and development $(18 ; 31 ; 43 ; 44 ; 45)$ as well as the opportunity to influence the improvement of home care work.

$\mathrm{HCNs}$ in our study emphasized home care nursing as meaningful, both increasing work motivation and the belief to continue working. The meaningfulness was considered as an intrinsic motivation for the home care nursing itself, and consistent with previous research $(15 ; 17 ; 31)$. Lack of motivation as a barrier to continue to work until retirement age was mentioned only a few times in our study, supporting that motivation does not generally decrease with age (17). However, external response and recognition from employers, clients, and relatives increased work motivation in our study. Supportive colleagues, a good workplace community, and good teamwork improved both work motivation and beliefs to continue working, which is also supported by earlier research $(18 ; 31 ; 32)$. Satisfaction with work and to be seen as a person is important when an ageing worker decides whether to continue working life (46). To ensure the 
quality of home care $(1 ; 18)$, enhancing HCNs' intrinsic work motivation and meaningfulness of work is therefore worthwhile.

Since work ability can be described as balance between individual resources and work demands (47), interventions need to pay attention to the complexity of work life (43) and be performed in parallel on different levels (8). However, to strengthen the positive aspects of work is of great importance, since positive emotions at work increase the perceived meaning of home care work (31), and make nurses work better (18), and continue to work (32). Personal resources as self-efficacy play similar roles as job resources (21). Self-efficacy is important in nursing (44) and in older workers' work context (19), connected to motivation and wellbeing at work $(19 ; 20 ; 21)$, helping workers control and affect their work environment (48). Enhancing self-efficacy might improve work motivation among nurses (49). As an important prognostic factor for work ability among HCNs, focus on factors such as self-efficacy are recommended in workplace interventions to promote work ability (8). Self-efficacy can be developed by mastery experiences by overcoming challenging obstacles, learning and modelling by seeing peers succeed, positive feedback, group support and encouragement until one starts believing in one's own abilities (50). Due to the results in our study, leaders engaging in dialogues with HCNs, actively expressing feedback and support, and inviting HCNs to influence their work with their great knowledge, could facilitate HCNs' belief to continue working. Ageing HCNs' desired challenges, which were balanced within the limit of resources, and by overcoming them, self-efficacy might be enhanced. By offering regular education to older workers, their self-efficacy can improve (51). A wealthy work community, and feedback and support from workmates provided belief in our study, and employers should make opportunities for team and informal meetings among home care staff, also stated by Tourangeau et al (31). Working in a pair with a team member might facilitate modelling from more experienced HCNs.

Although positive aspects of ageing are publicized, negative attitudes against older workers are still present $(44 ; 52 ; 53)$. Notably, in our study only a few HCNs mentioned their ageing as a concern. Still, they wanted the employers to notice their age in a positive manner, not as a barrier. Changes of managers' attitudes to ageing workers were considered important, since managers have the opportunity to influence factors to improve ageing workers' working life (53). Likewise, societal demands on increased workplace measures might further stress companies to implement strategies to retain older workers in work life (43; 52; 53). Due to high individual differences among ageing workers, they should not be seen as a homogenous group (14). To increase the willingness of ageing workers to continue to work, not only chronological age, but also factors due to biological, mental, and social age should be addressed in addition to other important areas (43). The worker's decision as to whether to remain in work or not, is linked to considerations about individual health, private economy, social inclusion and participation and self-fulfillment by meaningful and stimulating activities. Holistic adaptions taken must be on individual, organizational and company levels (43). A good interplay between the worker and the working environment, taking the workers' capacities and the work requirements into account to attain a good balance between individual resources and work demands, is needed for sustainable employment (54). To meet real problems faced by workers and employers, positive examples must be emphasized and negative patterns decreased (52). Although age management is not aimed towards a certain age group, 
addressing the needs of ageing workers could help employers in the health care sector deal with the lack of skilled workers, and in turn receive more workers with better well-being, better work ability and possibly longer careers (33).

\subsection{Methodological considerations}

Using a cross-sectional study, prevalence of multiple outcomes could be measured, and a large amount of participants could be reached at the same time (55). All HCNs in the chosen region, aged 45 years and older, were invited, and were considered as representatives of older workers in the home care sector (56). Another strength of this study was the use of multi-methods, including both qualitative and quantitative analysis of the research data. The manifest qualitative analysis provided a deeper knowledge and understanding of the issues $(24 ; 29 ; 30)$. Moreover, the quantitatively measured frequencies of utterances gained reliability, since the focus of HCNs' experiences was acknowledged (24). However, there are some limitations when using a cross-sectional study. The outcomes in the participants are measured concurrently, describing the phenomena at a given point in time, and it is difficult to derive causal relationships (55). When using a questionnaire there is a risk of high numbers of dropouts. The response rate was $51 \%$, which could imply a possible bias of the outcome. In agreement with the close supervisors, who administered the survey, the use of paper-based and/or web-based questionnaire was decided. The response rate was slightly lower among the web-based respondents. Hence, some none-responding HCNs might have answered a paper-based survey. Moreover, the research data consisted of open-ended questions. The answers were often short, which despite manifest analysis, might have caused some interpretation bias $(30 ; 56)$. However, the response rate of the open-ended questions among the answering respondents was high (86-97\%, $n=202-227$ for each question), although the open-ended questions were placed last in quite a large-scaled survey. This indicated that HCNs had an interest to articulate their work motivation and belief in their capabilities to continue working. Another strength was that the findings not only highlighted aspects that motivates HCNs to perform work tasks, but also aspects of their internal feelings about caring appeared as an intrinsic motivation and a deeper meaning of the work.

The HCNs' responses were either in Swedish or Finnish language. None of the researchers had Finnish as their mother tongue, although two of them mastered Finnish well. In the case of linguistic doubts, a person with Finnish mother tongue, also skilled in health care, was consulted. The researchers' preunderstanding consisted of long experience in health care, occupational health service and rehabilitation as well as experience in qualitative research. In order to minimize the pre-understanding, the qualitative data analysis followed a structured procedure in several steps $(24 ; 29 ; 30)$. Dependability was established by repeatedly going back in the encoding, verifying the encoding to the meaning units and the openended answers, and checking the reliability of the categories $(24 ; 30 ; 56 ; 57)$. Notes about the encoding were made throughout the analysis process. To increase conformability, triangulation between researchers was used. Quotations were used to support authenticity in presented categories (Table 2) (24; 56). Moreover, our study addressed the explicit views of the ageing HCNs, in the context of both rural and urban areas, including home care services conducted by municipalities, cities, and social- and health 
services consortiums. The categories that emerged through manifest content analysis were considered logical and answering the purpose of the study. The findings from our study can likely be transferred to other Nordic countries, due to their similarities in home care service (2). Despite home care including distinct elements concerning care in clients' homes; the results might be transferable to ageing workers in other nursing contexts $(24 ; 30 ; 56)$. Due to the high amount of participants, a generalization to a broader population of ageing $\mathrm{HCNs}$ might be applicable.

\subsection{Practical implications}

The results of this study convey important understandings of the ageing HCNs' views of work motivation and belief in their own capabilities to continue working until the expected retirement age, which is beneficial when considering the work life of HCNs. The HCNs did not perceive ageing to be a concern. By emphasizing the positive aspects, offering overcoming challenges and learning opportunities, the HCNs' work motivation and belief to continue working can be strengthened. Addressing the needs of ageing HCNs could also help employers deal with the lack of workers in the home care sector. In turn, employers could receive more workers with better well-being and with possibly longer work careers.

\section{Conclusions}

Home care work was perceived as meaningful and stimulating, and through highlighting the positive aspects together with strengthening the work community, both work motivation and belief to continue working might be facilitated. Moreover, work related demands must be balanced against the workers' resources, in combination with a healthy leadership. The perceived health highly affected the belief in one's capability to continue working whereas this affected work motivation less. Ageing was not perceived to be a concern; the still wanted challenges, and desired to develop work related skills. By overcoming challenges,' belief in their capabilities to continue working may be enhanced.

\section{Abbreviations}

HCNs

Home care nurses

\section{Declarations}

\section{Ethical approval and consent to participate}

The study was performed in compliance with the ethical principles delineated by the Finnish National Board on Research Integrity and was approved by the Board for Research Ethics at Åbo Akademi University, Turku, Finland (dated April 12, 2018). All individual participants in the study received written information that completing the survey meant consent to participation in the study.

\section{Consent for publication}


Not applicable.

\section{Availability of data and materials}

The data is not publicly available but could be requested from corresponding author after ethical approval to take part of the dataset.

\section{Competing interest}

The authors declare that they have no competing interests.

\section{Funding}

No external funding.

\section{Authors' contributions}

SW: study design, data collection and analysis, interpreting the analysis, drafting the manuscript. AFW: study design, interpreting the analysis, involved in drafting the manuscript. LF: study design, interpreting the analysis, involved in drafting the manuscript. All authors read and approved the final manuscript.

\section{Acknowledgements}

Thanks to Hanna Rintala, RPT, for help with the Finnish-Swedish translations of the open-ended questions and in linguistic doubts.

\section{References}

1. Rest KD, Trautsamwieser A, Hirsch P. Trends and risks in home health care. JHLSCM. 2012;2(1):3453. doi:10.1108/20426741211225993.

2. Kröger T, van Aerschot L, Puthenparambil JM. Hoivatyö muutoksessa: Suomalainen vanhustyö pohjoismaisessa vertailussa (In Finnish) (Nursing in change. Finnish eldercare in Nordic comparison). Jyväskylä: University of Jyväskylä,; 2018. YFI Publications 6. https://jyx.jyu.fi/bitstream/handle/123456789/57183/978-951-39-7372-8.pdf? sequence $=1$ \&isAllowed $=\mathrm{y}$.

3. Changes in Nordic care work. and their effects on work-related problems for workers in long-term care. Rostgaard T, Mattiessen M, Kröger T, Mathews J, Strandell R, Stranz A, Vabo M. Copenhagen: VIVE - The Danish Centre for Social Science Research, 2019. Transforming Care Conference. http://www.transforming-care.net/wp-content/uploads/2019/06/Tine-Rostgaard-Work-tasks-andproblems-TCC-June-24-26th-2019.pdf.

4. Vuori J, Törnroos K, Ruokolainen M, Wallin M. Enhancing late-career management among aging employees - A randomized controlled trial. J Vocat Behav. 2019;115:103327. doi:10.1016/j.jvb.2019.103327. 
5. de Wind A, Geuskens GA, Ybema JF, Blatter BM, Burdorf A, Bongers PM, van der Beek AJ. Health, job characteristics, skills, and social and financial factors in relation to early retirement-results from a longitudinal study in the Netherlands. Scand J Work Env Hea. 2014;40(2):186-94. doi:10.5271/sjweh.3393.

6. Cloostermans L, Bekkers MA, Uiters E, Proper KI. The effectiveness of interventions for ageing workers on (early) retirement, work ability and productivity: a systematic review. Int Arch Occ Env Hea. 2015;88:521-32. doi:10.1007/s00420-014-0969-y.

7. Converso D, Sottimano I, Guidetti G, Loera B, Cortini M, Viotti S. Aging and work ability; The moderating role of job resources and personal resources. Front Psychol. 2018;2262(8):1-12. doi:10.3389/fpsyg.2017.02262.

8. Larsson A, Karlqvist L, Westerberg M, Gard G. Identifying work ability promoting factors for home care aides and assistant nurses. BMC Musculoskelet Disord. 2012;13:1-11. doi:10.1186/1471-247413-1.

9. World Alzheimer Report. An analysis of long-term care for dementia. Alzheimer's Disease International; 2013. https://www.alz.co.uk/research/WorldAlzheimerReport2013.pdf.

10. Genet N, Boerma W, Kroneman M, Hutchinson A, Saltman RB, editors. Home care across Europe. Current structure and future challenges. World Health Organization; 2012. 27 Observatory Studies Series. https://www.euro.who.int/_data/assets/pdf_file/0008/181799/e96757.pdf.

11. Employment projections. Fastest growing occupations. Bureau of Labor Statistics. U.S. Department of Labor. https://www.bls.gov/emp/tables/fastest-growing-occupations.htm. Accessed 19 Feb 2020.

12. Employment outlook by occupation. Occupational Barometer. Ministery of Economic Affairs and Employment of Finland, Centre for Economic Development Transport and the Environment, TE services - Public employment and business services. https://www.ammattibarometri.fi/kartta2.asp? vuosi=20i\&ammattikoodi=5322\&kieli=en. Accessed 23 Mar 2020.

13. Schalk R, van Veldhoven M, de Lange AH, De Witte H, Kraus K, Stamov-Rossnagel C, et al. Moving European research on work and ageing forward: Overview and agenda. Eur J Work Organ Psychol. 2010;19(1):76-101. doi:10.1080/13594320802674629.

14. Guglielmi D, Avanzi L, Chiesa R, Mariani MG, Bruni I, Depolo M. Positive aging in demanding workplaces: The gain cycle between job satisfaction and work engagement. Front Psychol. 2016;7:1224. doi:10.3389/fpsyg.2016.01224.

15. van Den Berg P. Characteristics of the work environment related to older employees' willingness to continue working: Intrinsic motivation as a mediator. Psychol Rep. 2011;109(1):174-86. doi:10.2466/01.09.10.PR0.109.4.174-186.

16. Deci EL, Connell JP, Ryan RM. Self-determination in a work organization. J Appl Psychol. 1989;74(4):580-590. doi:0021-9010/89/\$00.75.

17. Boumans NPG, de Jong AHJ, Janssen SM. Age-differences in work motivation and job satisfaction, the influence of age on the relationships between work characteristics and workers' outcomes. Int $J$ Ageing Hum Dev. 2011;73(4):331-50. doi:10.2190/AG.73.4.d. 
18. Toode K, Routasalo P, Suominen T. Work motivation of nurses: A literature review. IJNS. 2011;48:246-57. doi:10.1016/j.jjnurstu.2010.09.013.

19. Paggi ME, Jopp DS. Outcomes of occupational self-efficacy in older workers. Int J Ageing Hum Dev. 2015;80(4):357-78. doi:10.1177/0091415015607640.

20. Salanova M, Llorens S, Schaufeli WB. Yes I, can. I feel good, and I just do it! On gain cycles and spirals of efficacy beliefs, affect, and engagement. Appl Psychol-Int Rev. 2011;60(2):255-85. doi:10.1111/j.1464-0597.2010.00435.x.

21. Bakker AB, Demerouti E. Job Demands-Resources Theory: Taking stock and looking forward. J Occup Health Psychol. 2017;22(3):273-85. doi:10.1037/ocp0000056.

22. Rigotti T, Schyns B, Mohr G. A short version of the occupational self-efficacy scale. Structural and construct validity across five countries. JCA. 2008;16(2):238-55. doi:10.1177/1069072707305763.

23. Fullemann D, Gregor JJ, Brauchli R, Bauer GF. The key role of shared participation in changing occupational self-efficacy through stress management courses. J Occup Organ Psych. 2015;88:490510. doi:10.1111/joop.12124.

24. Kyngäs $H$, Mikkonen $K$, Kääriäinen $M$, editors. The application of content analysis in nursing science research. Switzerland: Springer; 2020. doi:10.1007/978-3-030-30199-6_4.

25. Ilmarinen J. Ageing workers. Occupat Environ Med. 2001;58(8):546-52. doi:10.1136/oem.58.8.546.

26. Tuomi K, Ilmarinen J, Jahkola A, Katajarinne L, Tulkki A. Work Ability Index. 2nd revised edition. Helsinki: Finnish Institute of Occupational Health; 1998.

27. Schaufeli WB, Bakker AB, Salanova M. The measurement of work engagement with a short questionnaire. A cross-national study. Educ Psychol Meas. 2006;66(4):701-16. doi:10.1177/0013164405282471.

28. Regnault A, Willgross T, Barbic S. On behalf of the International Society for Quality of Life Research (ISOQOL) Mixed Methods Special Interest Group (SIG). Towards the use of mixed methods inquiry as best practice in health outcomes research. JPRO. 2018;2:19. doi:10.1186/s41687-018-0043-8.

29. Elo S, Kyngäs H. The qualitative content analysis process. J Adv Nurs. 2008;62(1):107-15. doi:10.1111/j.1365-2648.2007.04569.x.

30. Graneheim UH, Lundman B. Qualitative content analysis in nursing research: concepts, procedures and measures to achieve trustworthiness. Nurs Edu Today. 2004;24:105-12. doi:10.1016/j.nedt.2003.10.00.

31. Tourangeau A, Patterson E, Rowe A, Saari M, Thomson H, Macdonald G, Cranley L, Squires M. Factors influencing home care nurse intention to remain employed. Nurs Manag. 2014;22:1015-26. doi:10.1111/jonm.12104.

32. Gyllensten K, Wentz KAH, Håkansson C, Hagberg M. Older assistant nurses' motivation for a full or extended working life. Ageing Soc. 2018;1-15. doi:10.1017/S0144686X18000740.

33. Merkel S, Ruokolainen M, Holman D. Challenges and practices in promoting (ageing) employees working career in the health care sector - case studies from Germany, Finland and the UK. BMC 
Health Serv Res. 2019;19:918. doi:10.1186/s12913-019-4655-3.

34. Nilsson K. Conceptualisation of ageing in relation to factors of importance for extending working life - a review. Scand J Public Health. 2016;44:490-505. doi:10.1177/1403494816636265.

35. Nilsson K, Rignell Hydbom A, Rylander L. How are self-related health and diagnosed disease realted to early or deferred retirement? A cross-sectional study of employees aged 55-64. BMC Public Health. 2016;16:886. doi:10.1186/s12889-016-3438-6.

36. Andersen LL, Jensen PH, Sundstrup E. Barriers and opportunities for prolonging working life across different occupational groups: the SeniorWorkingLife study. Eur J Public Health. 2019;30(2):241-6. doi:10.1093/eurpub/ckz146.

37. Poulsen OM, Fridriksson JF, Tomasson k, Midtsundstad T, Mehlund IS, Hilsen Al, Nilsson K, Albin M. Working environment and work retention. Nordic Council of Ministers; 2017. TemaNord. 2017;559. http://norden.diva-portal.org/smash/record.jsf?pid=diva2\%3A1167099\&dswid=8650.

38. Doyle YG, McKee M, Sherriff M. A model of successful ageing in British populations. Eur J Public Health. 2012;22(1):71-6. doi:10.1093/eurpub/ckq132.

39. Schaufeli WB, Taris TW. A critical review of the Job Demands-Resources Model: Implications for improving work and health. Bridging Occupational, Organizational and Public Health. Dordrecht: Springer; 2014;pp. 43-68. doi:10.1007/978-94-007-5640-3_4.

40. deJonge J, Le Blanc PM, Peeters MCW, Noordam H. Emotional job demands and the role of matching job resources: A cross-sectional survey study among health care workers. IJNS. 2008;45:1460-9. doi:10.1016/j.ijnurstu.2007.11.002.

41. Xantopoulou D, Bakker AB, Dollard MF, Demerouti E, Schaufeli WB, Taris TW, Schreurs PJG. When do job demands particularly predict burnout? The moderating role of job resources. J Manag Psychol. 2007;22(8):766-86. doi:10.1108/02683940710837714.

42. Bakker AB, Sanz-Vergel Al. Weekly work engagement and flourishing: The role of hindrance and challenge job demands. J Vocat Behav. 2013;83:397-409. doi:10.1016/j.jvb.2013.06.008.

43. Nilsson K. A sustainable working life for all ages - The swAge-model. Appl Ergon. 2020;86:103082. doi:10.1016/j.apergo.2020.103082.

44. van der Heijden $B$, Peeters $M$, Le Blanc $P$, van Breukelen J. Job characteristics and experience as predictor of occupational turnover intention and occupational turnover in the European nursing sector. J Vocat Behav. 2018;108:108-20. doi:10.1016/j.jvb.2018.06.008.

45. Andersen LL, Thorsen SV, Larsen M, Sundstrup E, Boot CRL, Rugulies R. Work factors facilitating working beyond state pension age: Prospective cohort study with register follow-up. Scand J Work Environ Health. 2020. doi:10.5271/sjweh.3904. May.

46. Nilsson K. The influence of work environmental and motivation factors on seniors' attitudes to an extended working life or to retire. A cross sectional study with employees 55-74 years of age. JSS. 2017;5:30-41. doi:10.4236/jss.2017.57003.

47. Ilmarinen J. Promoting active ageing in the workplace. EU-OSHA. 2012. https://osha.europa.eu/en/tools-and-publications/publications/articles/promoting-active-ageing-in- 
the-workplace.

48. Bakker AB, Schaufeli WB, Leiter M, Taris TW. Work engagement: An emerging concept in occupational health psychology. Work Stress. 2008;22:187-200. doi:10.1080/02678370802393649.

49. Gupta J. Motivating health care workers: The role of nurse mentoring in low- and middle-income countries. ProQuest Information \& Learning. 2019. Dissertation abstract. ISBN 978-1392067130.

50. Bandura A. On the functional properties of perceived self-efficacy revisited. J Manag. 2012;38(1):944. doi:10.1177/0149206311410606.

51. Hsu LL, Chang WH, Hsieh SI. The effects of scenario-based simulation course training on nurses' communication competence and self-efficacy: A randomized controlled trial. J Prof Nurs. 2015;31(1):37-49.

52. Widell Blomé M, Borell J, Håkansson C, Nilsson K. Attitudes toward elderly workers and perceptions of integrated age management practices. Int J Occup Saf Ergon. 2020;26(1):112-20.

53. Nilsson K. Managers' attitudes to their older employees: A cross-sectional study. Work. 2018;59:4958. doi:10.1016/j.profnurs.2014.05.007.

54. Oakman J, Neupane S, Proper KI, Kinsman N, Nygård CH. Workplace interventions to improve work ability: A systematic review and meta-analysis of their effects. Scand J Work Env Hea. 2018;44(2):134-6. doi:10.5271/sjweh.3685.

55. Cummings C. Cross-sectional design. In: Allen M, editor. The SAGE Encyclopedia of Communication Research. Thousand Oaks: SAGE Publications; 2017. pp. 315-7. doi:10.4135/9781483381411.n118.

56. Elo S, Kääriäinen M, Kanste O, Pölkki T, Utriainen K, Kyngäs H. Qualitative Content Analysis: A Focus on Trustworthiness. SAGE Open 2014;1-10. doi:10.1177/2158244014522633.

57. Bengtsson M. How to plan and perform a qualitative study using content analysis. Nursingplus Open. 2016;2:8-14. doi:10.1016/j.npls.2016.01.001.

\section{Figures}




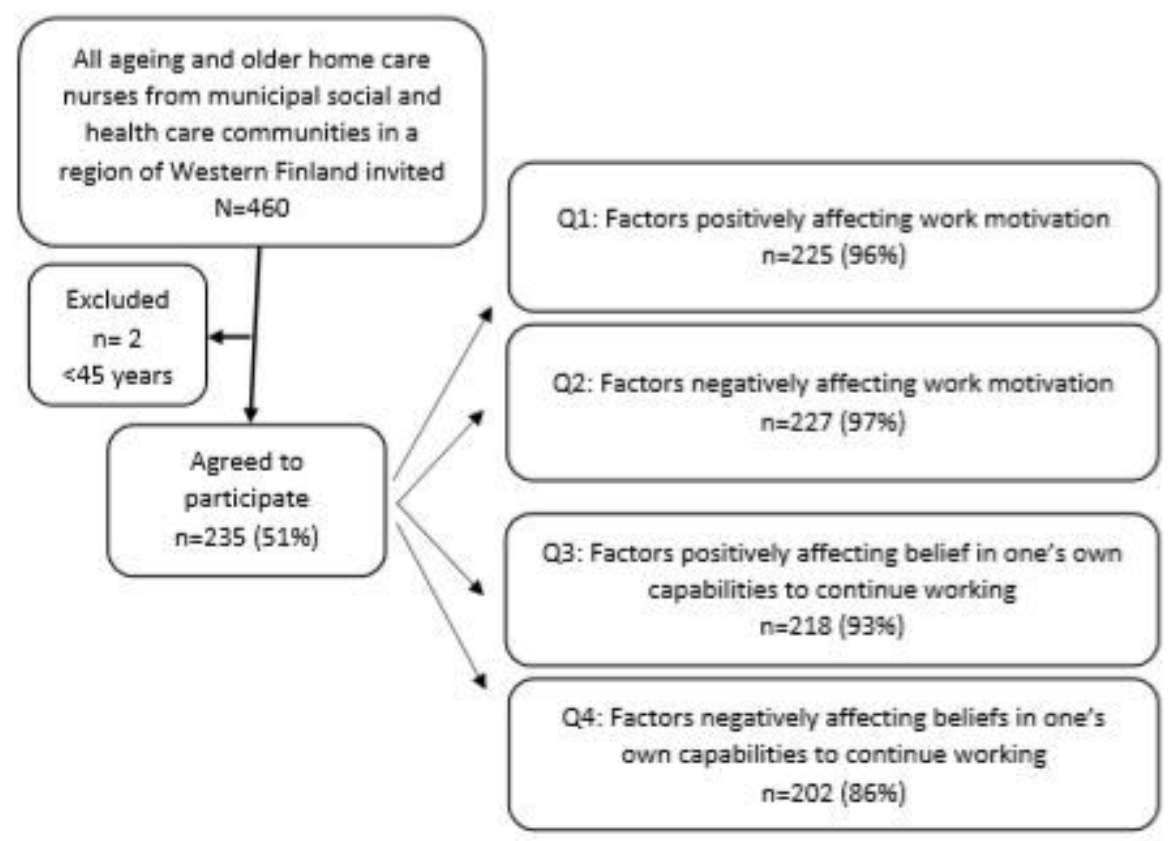

\section{Figure 1}

Flowchart of the study population

Work motivation

(659 utterances)

-Work environment

- Significance of the work

- Stimulating challenges

- External response

Income stability

Close relationships and leisure

Sufficient health and energy

- Organizational work environment

- Time constraints

- Job characteristics

-Work community

Weakened health and energy

Feedback from clients and relatives

Salary level

Staff shortage

National controlled decrees

Age

(620 utterances)
POSITIVELY

AFFECTING
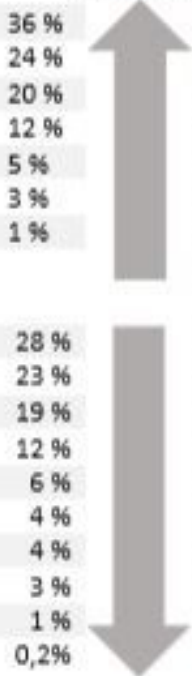

NEGATIVELY

AFFECTING
Belief in one's capabilities to work until the retirement age

(553 utterances)
* Own health $25 \%$

*Workplace resources $21 \%$

*Meaning of the work $\quad 18 \%$

- Nature of the work $17 \%$

Family life and leisure $\quad 6 \%$

Joy of living and wisdom $\quad 6 \%$

Income needed $\quad 3 \%$

Appreciation and feedback $\quad 3 \%$

*Health-related decline $\quad 29 \%$

*Multifaceted work $23 \%$

- Organizational resources $\quad 19 \%$

*Work related strain $\quad 13 \%$

Political and national decisions $\quad 5 \%$

Workplace community $\quad 4 \%$

Low income $\quad 4 \%$

Retirement and family life $\quad 1 \%$

Lack of motivation $1 \%$

Unemployment $\quad 1 \%$

(507 utterances)

- Categories with most responses, closer described in text

\section{Figure 2}

Categories of positively and negatively affecting aspects of work motivation and belief in one's capabilities 


\section{Supplementary Files}

This is a list of supplementary files associated with this preprint. Click to download.

- AdditionalFile1.QuestionnairetranslatedEnglish.docx 